\title{
EDITORIAL
}

\section{El reto de nuestra medicina interna: investigación y publicación}

\section{The challenge of our internal medicine: research and publication}

\section{Sonia Indacochea-Cáceda'}

La Unesco reconoce la investigación científica como "bien común" y que un "personal con talento y capacitado constituye la piedra angular de la capacidad de un país para la investigación y el desarrollo experimental".

Desde nuestra revista queremos sumarnos a ser parte del bien común de nuestra sociedad médica promoviendo la investigación a nivel nacional, lo cual hará que las siguientes generaciones médicas tengan mayor disponibilidad de conocimientos y experiencias de la medicina en nuestro país. También nuestro objetivo es colaborar en la formación integral de los médicos internistas, especialmente desde en el ámbito académico, sin descuidar los aspectos éticos y humanísticos. Ellos son cimiento de la medicina interna en el país.

En esta misma línea, la Unesco define como ciencia al "proceso en virtud del cual la humanidad, actuando individualmente o en pequeños o grandes grupos, hace un esfuerzo organizado, mediante el estudio objetivo de los fenómenos observados y su validación a través del intercambio de conclusiones y datos y el examen entre pares, para descubrir y dominar la cadena de causalidades, relaciones o interacciones; reúne subsistemas de conocimiento de forma coordinada por medio de la reflexión sistemática y la conceptualización; y con ello se da a sí misma la posibilidad de utilizar, para su propio progreso, la comprensión de los procesos y de los fenómenos que ocurren en la naturaleza y en la sociedad"; entonces, el desarrollo científico en las diferentes disciplinas es, sin lugar a dudas, fundamental para el desarrollo de un país.

Las grandes transformaciones ocurridas en este siglo se deben a la generación de conocimientos científicos y a los avances tecnológicos. Por tanto, resulta cada vez más relevante considerar tres factores imprescindibles para el desarrollo de las sociedades: la ciencia, la tecnología y la innovación. Estos factores impactan positivamente en el desarrollo económico, social y del medio ambiente así como en una mejor calidad de vida y salud. ${ }^{2}$

En la Primera Conferencia Latinoamericana sobre Investigación e Innovación para la Salud, celebrada en abril de 2008 en Río de Janeiro, Brasil, se documentó que el porcentaje del PBI dedicado a actividades de innovación y desarrollo fue inferior a 1,0\% en todos los países, con la excepción de Brasil. ${ }^{3} \mathrm{El}$ gasto en ciencia y tecnología también presentó una amplia variación, con las mayores inversiones en Argentina, Brasil y Chile. La producción científica en salud por millón de habitantes, según las publicaciones indizadas por el ISI, fue mayor en Chile, Argentina, Uruguay y Brasil y menor en El Salvador, Honduras y Perú. El número de investigadores

I. Médico internista y presidente de la SPMI
Indacochea-Cáceda S. El reto de nuestra medicina interna: investigación y publicación. Rev Soc Peru Med Interna. 2019;32(I):3.
(I \& D) por millón de habitantes entre 1990 y 2005 fue de 226 en Perú vs. 344 en Brasil.

La región de América Latina solo tiene el 3,6\% de los investigadores en el mundo y el 5,1\% de las publicaciones a nivel mundial. Entre los países que destacan en la región están Brasil y Chile. De forma general, las mujeres constituyen una minoría en el mundo de la investigación. ${ }^{4}$ Según la Clasificación Mundial de Universidades QS, edición 2013, y las ediciones posteriores, las universidades peruanas tienen menor producción científica que otros países de América Latina y, por tanto, menos publicaciones en revistas indizadas. ${ }^{5}$ Esta menor producción científica ya estaba descrita en 2005 , donde se hacía evidente una serie de deficiencias a ser consideradas de parte de los autores, de los editores, de los entes auspiciadores y de los lectores. ${ }^{6}$

Todo esto lleva a la urgencia de promover la investigación primero desde el Estado como política pública y desde las universidades y las instituciones científicas y académicas como la nuestra; pero, sobre todo nos debe llevar a motivar a nuestros estudiantes de medicina, residentes e internistas jóvenes a comprometerse con la investigación y a contribuir de esta manera al desarrollo de la medicina en el Perú.

Un estudio sobre la calidad de las revistas médicas en el Perú, realizado de 2005 a 2007, mostró que existía una gran variedad de revistas biomédicas, pocas están indizadas y solo una estaba en Medline; y, que la producción de investigación original no es alta. ${ }^{7}$ El panorama no ha cambiado mucho en los últimos años, con la excepción de que ahora tenemos dos revistas indizadas en Medline.

La calidad de la revista Revista de la Sociedad Peruana de Medicina Interna dependerá de la calidad de las investigaciones que incentivemos y de las que participemos de manera activa. Dejo la invitación a cada uno de ustedes.

\section{REFERENCIAS BIBLIOGRÁFICAS}

I. Unesco 2017: Conferencia General sobre Educación, Ciencia y Cultura Recomendación sobre la Ciencia y los Investigadores Científicos.

2. Soriano Álvarez C. Investigación científico-médica en el Perú: nuevos espacios [editorial]. Rev Gatroenterol Perú. 2013;33(3):207-8.

3. Alger J, Becerra-Posada F, Kennedy A, et al., Grupo Colaborativo de la Primera Conferencia Latinoamericana de Investigación e Innovación para la Salud. Sistemas nacionales de investigación para la salud en América Latina: una revisión de 14 países. Rev Panam Salud Pública. 2009; 26:447-57.

4. Unesco: Sobre la Ciencia al 2030. Resumen ejecutivo. Ediciones Unesco 2015

5. QS Quacquarelli Symonds. QS World University Rankings 2013 [Internet] London: Quacquarelli Symonds; 1994-20I3. URL disponible en: http://www. topuniversities.com/university-rankings/worlduniversity-rankings/2013\#sortin $\mathrm{g}=$ rank + region $=+$ country

6. Pamo Reyna O. Estado actual de las publicaciones periódicas científicas médicas del Perú. Rev Med Hered. 2004;16:65-73.

7. Huamaní C, Pacheco J. Visibilidad y producción de las revistas biomédicas peruanas. Rev Gastroenterol Perú. 2009;29-2:132-139. 